\title{
Una Geografía en Acción para Revolucionar la Naturaleza
}

Diana Alejandra Méndez Rojas ${ }^{1}$

\section{BOOK REVIEW}

Reinaldo Funes Monzote. Nuestro viaje a la Luna. La idea de la transformación de la naturaleza en Cuba durante la Guerra Fría. (La Habana: Casa de las Américas, 2019). 


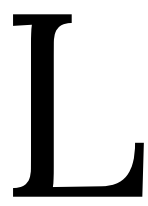

as revoluciones no sólo transforman las relaciones sociales, también modifican los vínculos entre los seres humanos y la naturaleza, al sumar voluntades y servirse de conocimientos puntuales. El historiador Reinaldo Funes Monzote ${ }^{2}$ da seguimiento a este binomio a través del cambio histórico que aconteció en Cuba tras el triunfo de la Revolución en 1959. El suceso más significativo en la historia de la Guerra Fría Latinoamericana, mayormente conocido en lo político y social que en lo ambiental. ${ }^{3}$ El libro aborda diferentes facetas del proceso de transformación socialista de la naturaleza en la búsqueda del desarrollo económico que, a partir de la década de 1960, asumió como metáfora que el esfuerzo por incidir a gran escala en la naturaleza sería el viaje a la Luna de los cubanos. Se trata de una alegoría precisa pues las dimensiones de los proyectos -agrícolas, hidráulicos y urbanos- demandaron la planificación de la economía y un esfuerzo social sostenido para "ordenar el presente y prever el futuro". La imagen lunar denota con claridad el entusiasmo que generaron los avances científicos y tecnológicos internacionales de la época que -además de la carrera por la "conquista" del espacio- desafiaron a la naturaleza al crear lluvia artificial, implementar la energía nuclear e incluso, aspirar a cambiar el clima terrestre. Funes Monzote muestra que en el caso cubano el emplazamiento transformador otorgó un nuevo papel a los geógrafos y científicos que incidieron en el curso revolucionario tanto por compartir sus conocimientos y habilidades como por vincularse con sus pares en el resto del mundo, y de forma particular con los de la Unión Soviética, ${ }^{4}$ la China comunista y los Estados Unidos. Es esta la ruta de lectura que el libro abre al lector para adentrarse a los alcances y contradicciones de la construcción del paisaje revolucionario.

La propuesta teórico metodológica del autor se inscribe en un diálogo entre la historia ambiental y la global. Conjunción que le permite dar seguimiento a los

\footnotetext{
${ }^{2}$ Investigador con amplia trayectoria en la historia ambiental, entre sus obras dedicadas a Cuba destacan: Reinaldo Funes Monzote, De bosque a sabana. Azúcar, deforestación y medio ambiente en Cuba: 1492-1926, (México: Siglo Veintiuno Editores- Estado Libre y Soberano de Quintana Roo, 2000); Reinaldo Funes Monzote, El despertar del Asociacionismo científico en Cuba (1876-1920), (Madrid: Consejo Superior de Investigaciones Científicas, 2004).

${ }^{3}$ Un volumen reciente que ha abierto nuevas reflexiones ambientales en el período de la Guerra Fría es: Andra Chastain \& Timothy Lorek (eds.), Itineraries of Expertise. Science, Technology, and the Environment in Latin America's Long Cold War, (Estados Unidos, University of Pittsburgh Press, 2020). Un libro que discute las diferentes expresiones de la Guerra Fría en América Latina es: Daniela Spencer (Coord.), Espejos de la Guerra Fría: México, América Central y el Caribe, (México, CIESAS, SRE, Miguel Ángel Porrúa, 2004).

${ }^{4}$ Un trabajo que también aborda la relación entre la Unión Soviética y América Latina sobre cuestiones agrícolas en la Guerra Fría es: Vanni Pettiná, "Mexican-Soviet Encounters in the Early 1960s. Tractors of Discord", en Thomas C. Field Jr. \& Stella Krepp \& Vanni Pettiná, Latin America and the Global Cold War, (Estados Unidos, The University of North Carolina Press, 2020).
} 
cambios en el pensamiento geográfico mundial y local, a las ideas ambientales en el ámbito internacional, así como a las tendencias en la ciencia y tecnología cubanas avocadas a la modernización y conservación en la segunda mitad del siglo XX. Para ello, aplica la categoría de geotransformación -acuñada por el geógrafo y revolucionario cubano Antonio Núñez Jiménez- expresión de un ideario geográfico en acción dedicado a la transformación y preservación del paisaje que relegó una vertiente determinista de la geografía para poner en el centro al ser humano como agente activo del medio. Lo que también significó que la disciplina asumiera su compromiso social en la construcción de una nueva sociedad. Cronológicamente, el libro inicia en el año de 1947 cuando comenzaron a sentarse las bases científicas y económicas para la escalada transformadora, se detiene en el intervalo de 1959 a 1989 cuando las obras científicas se vigorizaron -sobre todo durante la "ofensiva revolucionaria"- y concluye en el período especial de la década de 1990 provocado por la desintegración de la Unión Soviética. Suceso que cerró un horizonte de ascenso económico e inició una crisis que, tras el colapsó de los sistemas agroindustriales, abrió una transición agroecológica cimentada en una nueva perspectiva para la protección de la naturaleza junto a la vida humana. A cada uno de estos segmentos corresponde un apartado de la obra, que a su vez se dividen en capítulos.

Funes Monzote inicia el volumen situando a Cuba en el escenario internacional del debate teórico sobre el desarrollo en su vinculación ideológica con la Guerra Fría, mostrando que a ambos lados de la "cortina de hierro" se asumió como objetivo final alcanzar el desarrollo económico. En esta visión, la excesiva dependencia de Cuba en la exportación de azúcar -asentada en la colonia y renovada por la Segunda Guerra Mundial- era la causa del subdesarrollo y motivo principal de la depredación natural de los bosques. Frente a lo cual el gremio geográfico se posicionó en afán de planificar la economía, diversificar la agricultura, explotar científicamente los recursos naturales y defender los valores de la naturaleza. Asimismo, se diseñaron planes que, pese a no ejecutarse, fueron signo de un ánimo por imaginar la geotransformación del territorio, fue el caso de la carretera a Isla de Pinos. 
Algunas de estas ideas, censuradas por la dictadura, tuvieron continuidad tras la Revolución y cobraron vigor con ciertas medidas, como: la promulgación de la reforma agraria, la meta de producir 10 millones de toneladas en zafra, el avance de la Brigada Che Guevara, la desecación de la Ciénega de Zapata, la entrada de la revolución verde en cultivos como la caña, el emplazamiento de campañas de reforestación, la construcción de sitios de conservación como el Complejo Las Terrazas y de reforma urbana-rural como el Cordón de La Habana, que buscó renovar los términos de la relación entre la capital y el medio rural al tiempo de abrir espacio a la participación de mujeres. Estos son algunos ejemplos de las vastas labores que se emprendieron y de las que da cuenta el libro. En otro registro, sobresalió la creación de la Comisión Nacional de la Academia de Ciencias de Cuba. A través de la cual se aglutinaron flujos de intercambio académico internacional que permitieron la movilidad de científicos y estudiantes, dedicados al despliegue de proyectos conjuntos como el estudio de suelos. Funes Monzote señala que a pesar de que fueron años convulsos con resultados limitados -guiados por un optimismo desmedido sobre la capacidad del pueblo para dar el gran salto al desarrollo- Cuba logró, entre 1970 y 1980, posicionarse como el país de avanzada en América Latina en los indicadores de salud, educación, nutrición y disminución de la pobreza. Ello a pesar del embargo comercial de Estados Unidos y de eventos naturales como sequías y huracanes que golpearon a la isla durante el período. Este análisis es relevante no sólo para adentrarse en los avatares del desarrollo en Cuba, sino también para debatir su curso en el resto de América Latina.

Esta obra se apoya en una revisión crítica de fuentes primarias, hemerografía y bibliografía especializada. En el primer caso, sobresale la incorporación de documentos provenientes de la Fundación Antonio Núñez Jiménez, en La Habana. En el segundo, destacan menciones a publicaciones periódicas como Bohemia, Revolución, Carteles y Granma, vehículos de expresión de la situación política y social cubana a lo largo del siglo XX. En el tercero, resalta la revisión puntual de la historiografía sobre las teorías del desarrollo y las publicaciones científicas de los geógrafos y otros profesionistas como urbanistas, higienistas y agrónomos. Mención especial merecen el abordaje de la producción académica de los geógrafos Salvador 
Massip, Sarah Ysalgué y Núñez Jiménez. De igual forma, se incluyen referencias sobre congresos, entrevistas, exposiciones, documentales y programas televisivos, que permiten a la narrativa de Funes Monzote recuperar el tono de la cotidianidad en que la apuesta por transformar la naturaleza se encarnó en la sociedad cubana. La amplitud y diversidad de recursos es reflejo del profundo conocimiento del autor sobre la historia cubana, y constituye uno de los principales aportes del libro pues permite al lector identificar materiales a los que se puede acercar con nuevas preguntas.

\section{REFERENCIAS}

Chastain, Andra, \& Lorek, Timothy (eds.), Itineraries of Expertise. Science, Technology, and the Environment in Latin America's Long Cold War, (Estados Unidos, University of Pittsburgh Press, 2020).

Monzote, Reinaldo Funes, De bosque a sabana. Azúcar, deforestación y medio ambiente en Cuba: 1492-1926, (México: Siglo Veintiuno Editores- Estado Libre y Soberano de Quintana Roo, 2000).

Monzote, Reinaldo Funes, El despertar del Asociacionismo científico en Cuba (18761920), (Madrid: Consejo Superior de Investigaciones Científicas, 2004).

Pettiná, Vanni, "Mexican-Soviet Encounters in the Early 1960s. Tractors of Discord", en Thomas C. Field Jr. \& Stella Krepp \& Vanni Pettiná, Latin America and the Global Cold War, (Estados Unidos, The University of North Carolina Press, 2020).

Spencer, Daniela (Coord.), Espejos de la Guerra Fría: México, América Central y el Caribe, (México, CIESAS, SRE, Miguel Ángel Porrúa, 2004). 